Article

\title{
Application of Protection Motivation Theory to Investigate Sustainable Waste Management Behaviors
}

\author{
Piyapong Janmaimool
}

Environmental Social Sciences Program, Department of Social Sciences and Humanities, School of Liberal Arts, King Mongkut's University of Technology Thonburi, 126 Prachauthit Road, Thungkru District, Bangkok 10140, Thailand; piyapong.jan@kmutt.ac.th; Tel.: +66-098-919-9559

Received: 8 May 2017; Accepted: 20 June 2017; Published: 22 June 2017

\begin{abstract}
The aim of this study is to explain individuals' engagement in sustainable waste management behaviors (SWMBs) based on the application of protection motivation theory (PMT). SWMBs include waste avoidance, green purchasing, reuse and recycle, and waste disposal behaviors. Considering the amount of solid waste generation per capita per day during the past 10 years, the statistical records from the Bangkok Metropolitan Administration (BMA) illustrate the increasing trend of solid waste generation from $1.18 \mathrm{~kg}$ per capita per day in 2005 to $1.28 \mathrm{~kg}$ per capita per day 2015. Many scholars have asserted that human beings should alter their behaviors to successfully reduce their environmental impact. Several environmental problems (e.g., air pollution, water pollution, and odors) caused by waste disposal are consequences of human behaviors; therefore, citizens' engagement in SWMBs should be widely promoted. This study applies PMT to explore how individuals' SWMBs are influenced by their perceived threats caused by environmental contamination from waste disposal and their perceived coping capability. The Bangkok metropolitan area was selected as a case study because it has faced serious waste management problems, caused by increasing amounts of solid waste over the last ten years. Questionnaire surveys were administered to 193 public and private office workers residing in the city of Bangkok. Multiple linear regression analyses were performed to justify the effects of individual threat appraisal and coping appraisal on SWMB engagement. The results illustrated that respondents' self-efficacy could explain all types of SWMBs. On the contrary, response efficacy was not a significant predictor of all behaviors. People's perceived severity of adverse consequences caused by pollutants could significantly explain their waste disposal and reuse and recycle behaviors, and the perceived probability of being impacted by pollutants could explain only reuse and recycling behaviors. Thus, PMT may be well suited for explaining low-cost and simple SWMBs that require less effort. To promote people's engagement in each type of SWMB, different communication campaigns should be established.
\end{abstract}

Keywords: sustainable waste management behaviors; protection motivation theory; pro-environmental behaviors; threat appraisal; coping appraisal

\section{Introduction}

Numerous cities throughout the world face environmental problems caused by increasing amounts of solid waste. Bangkok, the capital city of Thailand, is one of those cities. In 1997, the average amount of waste recorded by the Bangkok Metropolitan Administration (BMA) was about 8500 tonnes/day, double the amount of waste recorded in 1987, at 4200 tonnes/day. Although BMA spent a great amount of money managing this amount of waste, they were simultaneously forced to search for more sites for waste disposal. BMA put much effort into solving this problem and the waste management issue was finally included in the Fifth Bangkok Development Plan (1997-2001) [1], where two main waste management strategies were emphasized. The first strategy was 
the Waste Minimization Project; its purpose was to reduce the amount of solid waste by encouraging residents to reduce and separate waste before disposal [2]. The second strategy, the Middle Term Disposal Plan (1997-2006), aimed to develop a waste disposal system. Although the strategies were widely implemented by all 50 districts, amounts of solid waste still increased, and environmental problems caused by waste disposal still occurred. This was demonstrated by the amount of waste in 2015, more than 10,000 tonnes/day, and that was a combination of several different types of waste. In addition, considering the amount of solid waste generation per capita per day during the past 10 years, the statistical record by the Bangkok Metropolitan Administration (BMA) illustrates the increasing trend of solid waste generation from $1.18 \mathrm{~kg} /$ capita/day in 2005 to $1.28 \mathrm{~kg} /$ capita/day 2015 (see Figure 1). Currently, the amount of waste is still steadily increasing and waste disposal in the landfills has caused both environmental and health risks to residents [3-6]. The city of Bangkok urgently needs to enact effective solid waste management measures.

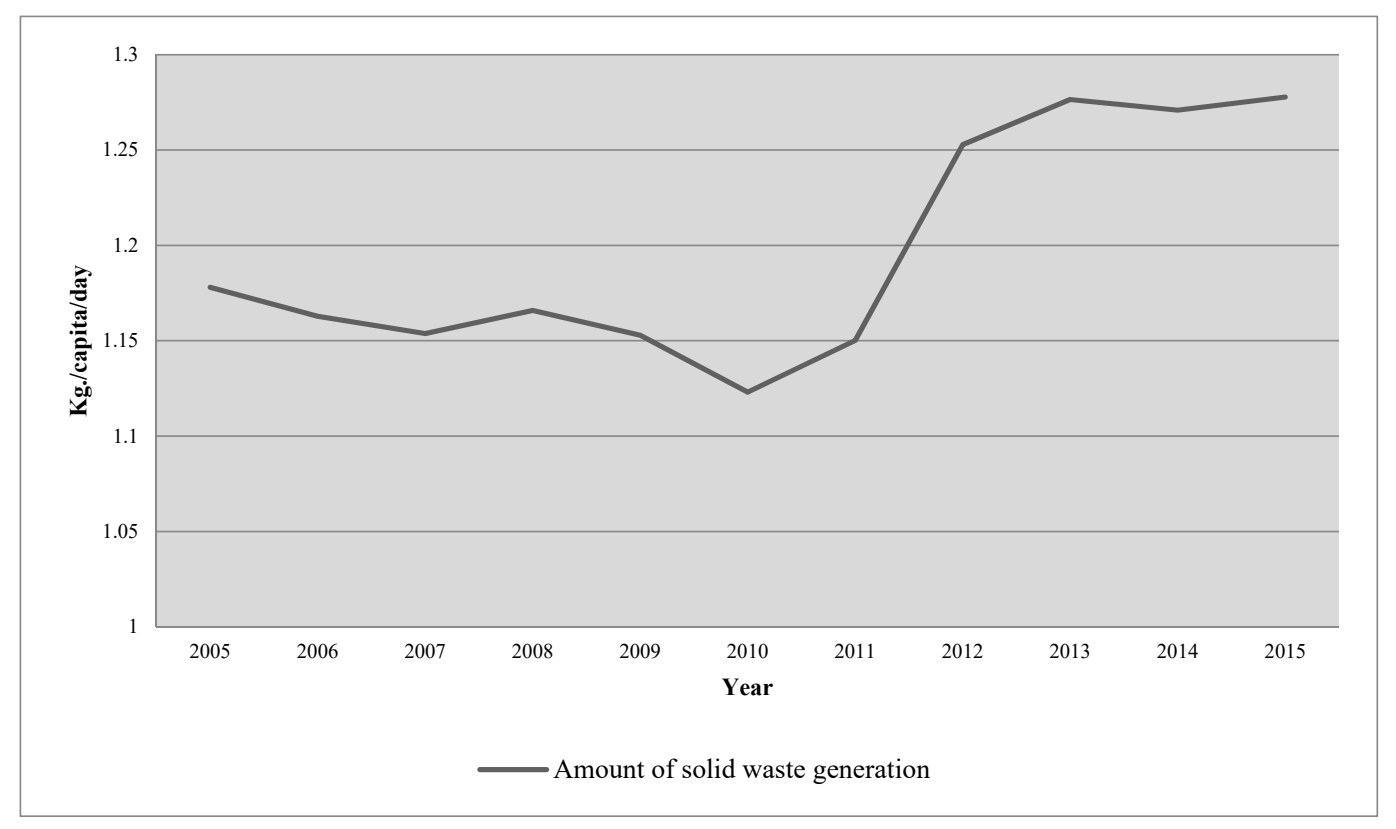

Figure 1. Amount of solid waste generation per capita per day.

The waste management behaviors of citizens can play an important role in solving waste management problems by minimizing the volume of solid waste and effectively eliminating waste by minimizing potential impacts on the environment [7-12]. The concept of a waste hierarchy, which is widely used to explore effective solid waste management [13-15], suggests three main strategies for achieving sustainable waste management: avoidance, resource recovery, and disposal [7]. Avoidance, the highest priority, refers to action to minimize the volume of waste produced by individuals, the industrial sector, and/or public and private organizations. Individuals, for instance, purchase products with the least packaging or that are produced from the fewest resources. In another way, individuals may avoid using single-use materials. If avoidance cannot be carried out, resource recovery practices are suggested. This means increasing the options for reuse, recycling, and reprocessing. Examples of reuse activities include double-sided printing, using single-sided paper for writing notes, and reusing plastic bags [16]. If neither waste minimization nor reuse can be performed, recycling waste should be considered. Several types of material, such as paper, glass, and plastic could be transformed into other usable products. In addition, energy recovery from waste is also proposed, since it was found that waste could be used to generate fuel and energy through a different waste process [17-22]. However, some types of waste, particularly hazardous waste, are not easy to reuse and recycle. Therefore, the last priority, disposal, is suggested. Here, disposal includes all disposal options that are carried 
out based on the notion of environmental responsibility and avoidance of environmental impacts. Disposing of solid waste in a landfill is the least desirable strategy due to the high possibility of yielding environmental impacts [23]. Similar to the waste hierarchy of the US-EPA, the EU waste hierarchy suggests five possible ways to practice waste management: reduction, reuse, recycle, recovery, and disposal [24]. All of these strategies can be implemented at all levels, from the individual to the municipality level. To successfully reduce environmental impacts, many researchers have asserted that humans should alter their behaviors, since many environmental problems are rooted in human behavior $[25,26]$. Several environmental problems (e.g., air pollution, water pollution, and odors) caused by waste disposal are consequences of human behaviors; therefore, citizens' engagement in sustainable waste management behaviors (SWMBs) should be widely promoted [3-6].

Several theoretical perspectives were employed to investigate which factors determine citizens' engagement in sustainable waste management behaviors. The theory of planned behaviors (TPB), initially proposed by Ajzen in 1991 [27], has been widely used to explain individuals' pro-environmental behavior (PEB). Based on TPB, PEB is influenced by behavioral intention, which is based on three important factors: subjective norms, attitudes toward behaviors, and perceived behavioral control [27]. Stern [28] proposed the value belief norm (VBN) theory in 1999; it included the moral dimension of the human decision-making process and perceived environmental values [28]. Though both theories can provide clear explanations on how environmental attitudes, positive attitudes towards PEB, and perceived normative social pressure could give rise to PEB, they could not provide an understanding of the potential motivators governing the PEB in the context of risk and uncertainty. In fact, both environmental and health risks faced by an individual can raise his/her motivation to perform an action to minimize those risks. In this study, the protection motivation theory (PMT) [29,30], addressing another theoretical perspective of PEB and emphasizing roles of risk perception on an individual's motivation to minimize potential impacts, is specifically investigated and discussed.

Originally developed to predict people's engagement in health risk prevention [30,31], PMT proposes motivational factors that may influence individuals' environmental awareness and pro-environmental behaviors. Based on PMT, when confronted with environmental and health risks, individual decisions to engage in preventative actions are made based on perceived risk vulnerability and the severity of the adverse consequences on the one hand, and the perceived potential to minimize those risks through the individual's perceived response efficacy and perceived self-efficacy on the other hand. When people have higher perceived severity, susceptibility as well as high perceived self-efficacy and response efficacy, they are likely to be involved in pro-environmental behaviors in order to minimize the risks. In considering the environmental risks that are potentially generated during the process of waste disposal, it was found that leachate and gas derived from waste disposal in landfills could potentially cause diverse environmental and health impacts such as explosions, vegetable damage, odors, polluted ground water, polluted air, and global warming [32]. In Bangkok city, massive fires at a rubbish dump and landfill explosions sometimes occur, and always cause polluted black smoke high into the sky, lasting for a period of time. As a result, Bangkok city sometimes faces a serious air pollution problem due to fires at rubbish dumps [5,6]. Based on this situation, it is possible that individuals' perceived risks and the capacity to manage those risks might influence their decision to take part in waste management behaviors.

This study aims to investigate citizens' engagement in sustainable waste management behaviors (SWMBs), which include waste avoidance, green purchasing, reuse and recycling, and waste disposal behaviors. In addition, the study also investigates how perceived environmental risks caused by waste disposal and perceived capability to manage those risks could explain citizens' engagement in SWMBs. Finally, the study proposes communication strategies that could promote SWMBs. 


\section{Protection Motivation Theory and Conceptual Idea of the Study}

The protection motivation theory (PMT), first introduced by Rogers [29], proposes a conceptual framework to explain factors predicting risk preventative behaviors. PMT assumes that individuals' decision to participate in risk preventative behaviors is made based on their motivation to protect themselves from threats such as natural disasters, global climate change, and nuclear explosion. People balance different risks and potential benefits. The decision is made based on the results of threat appraisal and coping appraisal [30]. Threat appraisal is a cognitive process that individuals use to estimate the level of threat. It includes two important elements: assessment of the perceived severity of the threat and the perceived probability of receiving adverse impacts from the threat (vulnerability). Perceived severity of the threat means the degree of seriousness of the possible harms that is perceived by an individual. Perceived vulnerability reflects an individual's perceptions of their susceptibility to the harms. Threat appraisal also includes the perception of the reward, which refers to perceived benefits of current practices (maintaining risky behaviors). These perceptions of vulnerability, severity, and the reward can motivate individuals to perform adaptive responses, such as pro-environmental behaviors. Higher perception of severity and vulnerability is likely to enhance individual motivation to perform risk preventative behavior, while higher perception of rewards from current practices will inhibit risk preventative behaviors. In addition to threat appraisal, coping appraisal, which refers to the estimation of an individual's capacity to perform risk preventative behaviors, also influences the protection motivation. The coping appraisal includes self-efficacy and response efficacy. Self-efficacy is an individual's perception of their capability to perform the behaviors. Response efficacy refers to the perceived effectiveness of the recommended risk preventative behaviors. Coping appraisal also considers the response cost, which is the cost of performing the recommended behavior [30]. A high cost of performing preventative behaviors might hinder people from being involved in recommended behaviors. The coping appraisal is the product of the appraisals of the self-efficacy and the response efficacy minus the costs of performing the recommended preventive behavior. The model predicts that the higher the response efficacy, self-efficacy, and the lower response cost, the more possible one will decide to perform adaptive behaviors.

PMT is primarily applied to explain people's decisions to partake in health risk mitigation behaviors [33,34] and disaster prevention [35-37]. A number of researchers have also applied PMT to explain pro-environmental behaviors. Kim et al. [38], for instance, found that individuals' intention to engage in pro-environmental behaviors was significantly influenced by many PMT attributes, including the perceived severity of the consequences associated with climate change, perceived response efficacy, and self-efficacy. Marquit [39] investigated how residents' perception of air pollution problems and threats to human health affected their engagement in pro-environmental behaviors, and the results showed that people in general tend to be involved in environmental behaviors that require minimal physical effort to carry out (e.g., driving fewer miles and avoiding idling) more than those requiring greater physical effort (e.g., riding a bicycle and walking). Keshavarz and Karami [40] also applied PMT to explore farmers' pro-environmental behaviors during a drought, and they found that a number of variables related to PMT (e.g., farmers' response efficacy, perceived severity, response costs, perceived vulnerability, and self-efficacy) as well as income and the social environment significantly predicted farmers' engagement in biodiversity conservation, environmental pollution reduction, soil and water resource protection, and the reduction of pressure on land and energy resources. Although a number of researchers have already investigated the application of PMT to explore pro-environmental behaviors, this study focuses particularly on SWMBs, which comprise several types of waste management behaviors; these behaviors require different levels and types of effort, such as financial, physical, and mental effort. Therefore, the potential of PMT to predict each type of SWMB could differ. If this difference is understood, it is expected that a strategy to encourage people to engage in each type of SWMB can be properly developed. 


\section{Conceptual Idea of the Study}

Since the waste disposal process potentially yields environmental and health risks [32], and also affects global climate change, it is possible that an individual's threat appraisal and coping appraisal, as indicated in PMT, will influence their engagement in waste management behaviors. Therefore, this study intends to explore the influence PMT attributes on people' engagement in sustainable waste management behaviors. With the purpose of providing impetus to the development of environmental risk communications which can contribute to behavioral changes, this study simplified the original PMT model, and selected to investigate only variables related to risk and coping assessments. Two independent variables are related to threat appraisal: the first is the perceived severity of adverse consequences potentially caused by the environmental impacts of waste disposal and the second is the perceived probability of receiving impacts from contaminated environments. Another two independent variables related to coping appraisal are self-efficacy and response efficacy. These four independent variables were examined to ascertain whether they could predict the level of engagement in waste management behaviors. The proposed relationship between the dependent and the independent variables is shown in Figure 2. It is assumed that individuals who exhibit a high level of perceived risks and perceived self-capability would be more active to perform waste management behaviors.

\section{Threat Appraisal}

\begin{tabular}{|c|c|}
\hline & \\
\hline $\begin{array}{l}\text { Perceived severity of adverse consequences } \\
\text { caused by environmental contamination }\end{array}$ & $\begin{array}{c}\text { Level of engagement in } \\
\text { waste management }\end{array}$ \\
\hline $\begin{array}{l}\text { Perceived probability of receiving impacts } \\
\text { from contaminated environments }\end{array}$ & $\begin{array}{l}\text { behaviors } \\
\text { avoidance beh }\end{array}$ \\
\hline Coping Appraisal & Green purchasing behaviors \\
\hline Self-efficacy & behaviors \\
\hline Response efficacy & Waste disposal behaviors \\
\hline
\end{tabular}

Figure 2. Conceptual idea of the study.

With regards to waste-management behaviours, many public and private organisations have made strong efforts to encourage their workers to act in an environmentally conscious way. For instance, some organisations currently provide waste-sorting bins in order to promote workers' engagement in waste separation. In public spaces, the Bangkok Metropolitan Administration (BMA) provides three types of bins in several locations throughout the 50 districts of Bangkok City: bins for reusable or recyclable waste, bins for general waste, and bins for hazardous waste [41]. The BMA, together with the Ministry of Public Health, also launched a campaign that aimed to minimise the use of foam containers [41]. Many restaurants in Bangkok City have replaced their foam food containers with paper containers. At the same time, the BMA encourages people to not support restaurants that use foam containers.

Additionally, green purchasing behaviours have recently started to be promoted in Bangkok City. Many green businesses have been strongly supported by financial institutions. Also, several types of consumer goods in Bangkok City are produced with concern for the environment. For instance, environmentally friendly materials are used instead of harmful materials. The use of recyclable and reusable materials—or simply less material—has been applied in the production of many products such as eco-friendly bottled water, products with eco-friendly packaging, or foods and drinks in returnable containers. To minimise the amount of plastic waste, consumers are also encouraged to use cotton shopping bags instead of plastic shopping bags when purchasing goods, and cotton bags are easily 
found in many convenience stores in Bangkok City. It can be said that both governments and public and private organisations are enthusiastically promoting sustainable waste-management behaviours by providing waste-management infrastructure and launching several campaigns. This study will investigate workers' engagement in four types of SWMBs including waste avoidance, green purchasing, reusing and recycling, and waste-disposal behaviours.

Currently, the solid waste of Bangkok City is generated from several sources, including the residential, tourist, commercial, and institutional sectors. In 2014, approximately 67 percent of the total waste was generated by households, institutions, and businesses; 33 percent was hazardous and nonhazardous industrial waste and hospital waste [42]. Of the solid waste that was sent to landfills daily in Bangkok City, 48 percent was organic waste such as food, branches, and leaves, and 14 percent was recyclable waste such as plastics, paper, glass, and metal. The proportion of nonrecyclable wastes such as rubber, fabric, and textiles was 38 percent [42].

To effectively manage metropolitan solid waste (MSW), the BMA established waste-management practices that include three separate processes: waste minimisation and separation, waste collection and transportation, and waste treatment and disposal [41]. Regarding waste minimisation and separation, the BMA has initiated several campaigns such as the three-R campaign ('Reduce, Reuse, and Recycle'), pilot waste-management projects at schools, and community-based solid waste management [43]. The BMA also provides garbage bins for waste separation at the source. For waste collection and transportation, almost 100 percent of the solid waste generated can be collected by the BMA, which uses 2200 vehicles to collect approximately 10,000 tons of waste per day [42]. All the collected waste is transported to three transfer stations located in the west, north, and east of Bangkok City; after that, private-sector workers contracted with BMA move the waste to landfills outside Bangkok City in the Chachoengsao and Nakhon Pathom provinces. Near the landfills, waste recycling is performed by the informal sector-that is, reusable and recyclable materials are gathered and sold by informal workers [43]. A BMA-contracted private company has an incinerator for treating hazardous waste, particularly contagious hospital waste [43].

The BMA has also employed many government laws for its waste management scheme. According to the Bangkok Metropolitan Administration Acts B.E. 1985, the BMA has a duty to provide waste management services to the private sector, governmental agencies, local administrations, and state-owned organisations, and the BMA can charge service fees. Additionally, the BMA Regulation on criteria from MSW and night soil from buildings, places, and public services places B.E. 2002 states that property owners have to separate their construction and demolition waste from their MSW and store them on their own property until collected by BMA upon request. The Public Cleansing and Orderliness Acts B.E. 1992 have been also enforced to control people's behaviours. In accordance with this act, people are not allowed to litter or excrete waste on roads or in public places [44]. The concept of the 'polluter pays principle' (PPP) was also applied in the National Environment Act B.E. 1992, which forces polluting factories to pay for the environmental damage they cause. This act encourages factories to install treatment devices that reduce pollution [44]. In addition to legislation, the BMA has also initiated campaigns to raise people's awareness of the significance of solid waste management and to encourage them to be involved in sustainable waste-management behaviours.

\section{Research Method}

In this study, the dependent variable was defined as citizens' engagement in each type of waste hierarchy behaviors. These behaviors were divided into four categories: waste disposal, green purchasing, waste avoidance or reduction, and reuse and recycle behaviors (see Table 1). The literature review reveals that many researchers employ individual self-reports when developing questionnaire items. Numerous studies showed that a self-report is an effective tool for measuring actual environmental behavior [45,46]. This study employed self-reports to collect data for measuring the dependent variable. Respondents were asked to indicate the frequency of their involvement in a list of waste management behaviors. The study developed a list of questions, adapted from 
Boer and Seydel [47], to measure the independent variables. Respondents were asked to indicate the degree of perceived severity of adverse consequences caused by environmental impacts of waste disposal, the perceived probability of receiving impacts from contaminated environments, the degree of self-capability to perform waste management behaviors, and the perceived capability of waste management behaviors to mitigate environmental impacts.

Table 1. Factors, variables, and development of questionnaire.

\begin{tabular}{|c|c|c|c|}
\hline Factors & Variables & Survey Questions & $\begin{array}{l}\text { Response } \\
\text { Categories }\end{array}$ \\
\hline \multirow{9}{*}{$\begin{array}{l}\text { Level of engagement in } \\
\text { hierarchy waste } \\
\text { management behaviors }\end{array}$} & \multirow{2}{*}{ - Waste disposal behaviors } & $\begin{array}{l}\text { How often do you separate waste into the proper } \\
\text { categories before throwing it away in bins? }\end{array}$ & \multirow{9}{*}{$\begin{array}{l}1=\text { Never } \\
5=\text { Regularly }\end{array}$} \\
\hline & & $\begin{array}{l}\text { Have you ever thrown the liquid from a container } \\
\text { away before throwing the container away? }\end{array}$ & \\
\hline & \multirow[b]{2}{*}{ - Green purchasing behaviors } & $\begin{array}{l}\text { Have you avoided buying food packaged in } \\
\text { foam containers? }\end{array}$ & \\
\hline & & $\begin{array}{l}\text { During the past year, how often have you purchased } \\
\text { environmentally friendly products, such as organic } \\
\text { products, biodegradable detergents, and } \\
\text { returnable containers? }\end{array}$ & \\
\hline & \multirow{3}{*}{ - Waste avoidance behaviors } & $\begin{array}{l}\text { How often do you use a cotton bag instead of } \\
\text { plastic bags? }\end{array}$ & \\
\hline & & $\begin{array}{l}\text { Have you ever refused to receive a plastic bag when } \\
\text { you buy a few items? }\end{array}$ & \\
\hline & & $\begin{array}{l}\text { Have you used a reusable instead of a single } \\
\text { use container? }\end{array}$ & \\
\hline & \multirow{2}{*}{ - Reuse and recycle behaviors } & $\begin{array}{l}\text { How often do you reuse or recycle things such as } \\
\text { plastic bags and bottles? }\end{array}$ & \\
\hline & & $\begin{array}{l}\text { Have you ever done double-sided printing and used } \\
\text { single-sided paper for writing notes? }\end{array}$ & \\
\hline \multirow{2}{*}{ Threat Appraisal } & $\begin{array}{l}\text { - Perceived severity of adverse } \\
\text { consequences caused by } \\
\text { environmental contamination }\end{array}$ & $\begin{array}{l}\text { How severely can environmental pollutants caused by } \\
\text { waste disposal affect humans? }\end{array}$ & \multirow{2}{*}{$\begin{array}{l}1=\text { Low } \\
5=\text { Very high }\end{array}$} \\
\hline & $\begin{array}{l}\text { - Perceived probability of } \\
\text { receiving impacts from } \\
\text { contaminated environments }\end{array}$ & What is the possibility that pollutants will impact you? & \\
\hline \multirow[t]{2}{*}{ Coping Appraisal } & - Self-efficacy & $\begin{array}{l}\text { Is it possible that you will be able to significantly } \\
\text { change your behaviors into sustainable waste } \\
\text { management behaviors? }\end{array}$ & \multirow{2}{*}{$\begin{array}{l}1=\text { Low } \\
5=\text { Very high }\end{array}$} \\
\hline & - Response efficacy & $\begin{array}{l}\text { Do you think a single person's actions can contribute } \\
\text { to the improvement of environmental quality? }\end{array}$ & \\
\hline
\end{tabular}

Public and private office workers who work in the city of Bangkok, Thailand were selected as a sampling group because the daily activities of these groups of people potentially produce a great amount of solid waste. Namely, regarding the nature of their jobs, these people are regularly involved in office activities that could produce a considerable amount of waste, such as paper, cardboard, plastics, textiles, or yard waste. In addition, regarding the lifestyles of office workers in Bangkok city, most office workers regularly eat out; as a result, they can produce many types of waste, such as drink containers, plastic bags, and food containers. Therefore, it is expected that changes in office workers' waste management behaviors could potentially minimize the metropolitan solid waste problems in Bangkok city.

The questionnaire surveys were carried out during April to May 2016. 120 questionnaire sheets were sent to office workers of public organizations such as the Department of Public Works and Town and Country Planning, Department of City Planning under the Bangkok Metropolitan Administration, and the Government Complex in Bangkok city, Thailand. The refusal rate was 20 percent, or approximately 95 questionnaire sheets were replied. However, only 71 completed questionnaire sheets could be used for the data analysis. In addition, online questionnaire surveys with 122 office workers of private companies were also carried out. In total, there were 193 sampling groups which included office workers of public or private companies. These sampling groups were also 
selected based on the nature of the job, including various types of office workers, such as accounting jobs, receptionists, customer service agents, and administrative assistants. Before participating in the questionnaire surveys, all participants had been asked to read the consent form. If they felt uncomfortable to be involved, they could withdraw or decide not to complete a questionnaire sheet.

For the data analysis, multiple linear regression analyses were performed to test how PMT attributes affect each type of SWMB. Prior to that, the internal consistency of the scales used to measure the variables was also evaluated. An appropriate level of internal reliability was judged based on Cronbach's alpha, which should be above 0.70. In this study, Cronbach's alpha was 0.765; therefore, data gained from the surveys were reliable. Then, all collected data were statistically analyzed by performing a multiple regression analysis to evaluate the proposed relationship between individuals' engagement in SWMBs (dependent variable) and potential predictors (independent variables). By performing a multiple regression analysis, the researcher was able to evaluate the impact of each PMT attribute on SWMBs [48]. Finally, all results were discussed, and implications for the development of environmental education and risk communication strategies were proposed.

\section{Results}

\subsection{Characteristics of Respondents}

The socio-demographic characteristics of the respondents are depicted in Table 2 . The number of female respondents was higher than that of male respondents, at $64.2 \%$ and $35.8 \%$, respectively. The average age of the respondents was 30.5 years old. The survey results showed that most of the participants had an average income of between 15,000 and 30,000 Baht. This amount coincides with a standard income for a person holding a bachelor's degree. The percentage of respondents with an average income of between 30,001 and 50,000 Baht, which was considered as a high income, was almost $25 \%$; whereas, only $6.2 \%$ had a low income, less than 10,000 Baht. The majority of the participants, approximately $59 \%$, worked with a private company, and $36.8 \%$ worked with a public organization. As to the respondents' education level, almost $60 \%$ of the participants have a bachelor's degree and $37.8 \%$ have a master's degree. The average period of time living in Bangkok was 18.5 years.

Table 2. Socio-demographic characteristics of the respondents.

\begin{tabular}{lcc}
\hline \multicolumn{1}{c}{ Items } & Mean/N & SD/(\%) \\
\hline Gender & & \\
\hline Male & 69 & $35.8 \%$ \\
Female & 124 & $64.2 \%$ \\
\hline Age & 30.5 & 7.5 \\
\hline Income (Baht) & & \\
\hline less than 10,000 & 12 & $6.2 \%$ \\
10,000-15,000 & 23 & $11.9 \%$ \\
15,001-30,000 & 83 & $43.0 \%$ \\
30,001-50,000 & 48 & $24.9 \%$ \\
More than 50,000 & 27 & $14.0 \%$ \\
\hline Career & & \\
\hline Private Company & 114 & $59.1 \%$ \\
Public Organization & 71 & $36.8 \%$ \\
Public-Private & 8 & $4.1 \%$ \\
\hline Company & & \\
\hline Period of Time Living in BKK & 18.5 & 11.9 \\
\hline Education Level & & \\
\hline High School & 15 & $7.8 \%$ \\
Bachelor's & 94 & $48.7 \%$ \\
Master's & 73 & $5.7 \%$ \\
Doctorate & 11 &
\end{tabular}

Notes: $N=193$. 


\subsection{Respondents' Engagement in SWMBs and Descriptive Statistics of Predictors}

In Table 3, the descriptive statistics of the constructs are presented. The average SWMB score was 3.52 , with a standard deviation of 0.67 on a scale of $1-5$. Considering each type of SWMB, participants reported high engagement in reuse and recycle behaviors, with an average score of 4.05 and a standard deviation of 0.86 . Compared to other SWMBs, engagement in waste avoidance behaviors had the lowest score, with an average score of 3.31 and a standard deviation of 0.80 . Green purchasing behaviors had an average score of $3.42(\mathrm{SD}=0.83)$, which is slightly higher than waste disposal behaviors, which had an average score of $3.40(\mathrm{SD}=0.94)$. Considering threat and coping appraisals, respondents reported high perceived severity of adverse consequences caused by environmental contamination, with an average score of 4.37 and a standard deviation of 0.75 ; perceived vulnerability had an average score of 3.79 and a standard deviation of 0.67 . Respondents reported slightly different levels of perceived self-efficacy and response efficacy; namely, $3.42(\mathrm{SD}=0.88)$ and $3.55(\mathrm{SD}=0.94)$, respectively. Table 3 also illustrates the reliability of scales presented as Cronbach's alpha values. All variables demonstrate good reliability with Cronbach's alphas above 0.70 . These results confirm that all corrected data are reliable and can be used to perform an inferential statistical analysis, such as a multiple regression analysis.

Table 3. Average sustainable waste management behavior (SWMB) score, descriptive statistics of potential predictors, and Cronbach's alpha.

\begin{tabular}{llccc}
\hline & \multicolumn{1}{c}{ Items } & Mean & SD & Cronbach' s $\alpha$ \\
\hline \multirow{2}{*}{$\begin{array}{l}\text { Waste management } \\
\text { behaviors }\end{array}$} & - Waste disposal behaviors & 3.40 & 0.94 & 0.71 \\
& - Green purchasing behaviors & 3.42 & 0.83 & 0.73 \\
& - Waste avoidance behaviors & 3.31 & 0.80 & 0.73 \\
& - Reuse and recycle behaviors & 4.05 & 0.86 & 0.71 \\
\hline \multirow{2}{*}{ Threat Appraisal } & - Perceived severity of adverse consequences & \multirow{2}{*}{4.37} & \multirow{2}{*}{0.75} & - \\
& caused by environmental contamination & & & - \\
& - Perceived probability of receiving impacts & 3.79 & 0.91 & - \\
\hline \multirow{2}{*}{ Coping Appraisal } & from contaminated environments & 3.42 & 0.88 & - \\
\hline
\end{tabular}

Notes: $N=193$.

\subsection{Influence of Threat Appraisal and Coping Appraisal on Respondents' Engagement in SWMBs}

To test whether perceived severity, perceived vulnerability, perceived self-efficacy, or perceived response efficacy could predict participants' engagement in SWMBs, multiple regression analyses were performed. Before investigating the predictors of each type of $S W M B$, the study first evaluated the predictors of overall SWMBs. Therefore, an average SWMB score was calculated and defined as the criterion variable. The selected predictors were the four indices. The results are reported in Table 4 . The overall model was significant with $\mathrm{F}(4,187)=15.817, p=0.000$. The multiple correlation coefficient (R) was 0.503 , and $R$ square was 0.253 . This indicates that approximately $25.3 \%$ of the variance in SWMBs can be accounted for by the linear combination of the four predictors. The variance inflation factor (VIF) was in the range of 1.13-1.27, which is below the threshold value of 10 [49]. This indicated that there was no multicollinearity. Regarding the influence of each variable on SWMBs, the results show that three variables could predict respondents' engagement in SWMBs. Perceived self-efficacy was the most significant variable; its beta-value is 0.382 . Perceived severity and vulnerability were also significant at $0.5 \%$. All three variables had a positive effect on SWMBs. Respondents reported high scores on these variables and tended to actively engage in SWMBs. Only one variable had no effect on SWMBs: perceived response efficacy. This implies that PMT can be applied to explore people's decision to engage in SWMBS and that enhancing respondents' perceived self-efficacy, severity, and vulnerability potentially promotes the practice of SWMBs. 
Table 4. Summary of regression analysis for variables predicting sustainable waste management behaviors.

\begin{tabular}{ccccc}
\hline \multirow{2}{*}{ Variable } & \multicolumn{5}{c}{ Waste Disposal Behaviors } \\
\cline { 2 - 5 } & B & SE B & $\beta$ & VIF \\
\hline Perceived severity & 0.15 & 0.06 & $0.17^{*}$ & 1.25 \\
Perceived probability & 0.10 & 0.05 & $0.14^{*}$ & 1.27 \\
Self-efficacy & 0.29 & 0.05 & $0.38^{* *}$ & 1.17 \\
Response efficacy & -0.03 & 0.05 & -0.04 & 1.13 \\
\hline $\mathrm{R}^{2}$ & \multicolumn{5}{c}{0.25} \\
Adjusted $\mathrm{R}^{2}$ & \multicolumn{5}{c}{0.24} \\
F for change in $\mathrm{R}^{2}$ & \multicolumn{5}{c}{15.82} \\
\hline
\end{tabular}

Notes: $N=193 ;{ }^{*} p<0.05,{ }^{* *} p<0.01$.

Table 5 shows the four multiple regression models for predicting each type of SWMB. Many variables related to PMT could predict respondents' engagement in waste disposal and reuse and recycle behaviors, whereas waste avoidance and green purchasing behaviors could only be predicted by perceived self-efficacy. First, the multiple regression model for predicting waste disposal behavior is significant, with $F(4,188)=17.534, p=0.000$. The multiple correlation coefficient $(\mathrm{R})$ was 0.521 , and $\mathrm{R}$ square was 0.277 . This indicates that approximately $27.7 \%$ of the variance in waste disposal behaviors could be accounted for by the linear combination of those selected predictors. There was no multicollinearity as a result of the VIF; the VIF values were in the range of 1.14-1.27. They were all below the threshold value of 10 [49]. Considering the influence of each factor on the behavior, it was found that perceived self-efficacy was significant at $1 \%$, while perceived severity was significant at $5 \%$. Perceived response efficacy and vulnerability did not show significant influence on waste disposal behavior. Second, the model for predicting green purchasing behavior was also significant with $\mathrm{F}(4,188)=6.788, p=0.000$. The multiple correlation coefficient $(\mathrm{R})$ was 0.355 , and $\mathrm{R}$ square was 0.126. Approximately $12.6 \%$ of the variance in green purchasing could be accounted for by the linear combination of selected independent variables. However, when considering the potential of each selected independent variable in predicting both types of PEBs, green purchasing behavior could only be predicted by perceived self-efficacy.

Table 5. Summary of regression analysis for variables predicting each type of sustainable waste management behaviors.

\begin{tabular}{|c|c|c|c|c|c|c|c|c|c|c|c|c|c|c|c|c|}
\hline \multirow{2}{*}{ Variable } & \multicolumn{4}{|c|}{ Waste Disposal Behaviors } & \multicolumn{4}{|c|}{ Green Purchasing Behaviors } & \multicolumn{4}{|c|}{ Waste Avoidance Behaviors } & \multicolumn{4}{|c|}{ Reuse and Recycle Behaviors } \\
\hline & B & SE B & $\beta$ & VIF & B & SE B & $\beta$ & VIF & B & SE B & $\beta$ & VIF & B & SE B & $\beta$ & VIF \\
\hline Perceived severity & 0.17 & 0.09 & $0.14 *$ & 1.25 & 0.02 & 0.08 & 0.02 & 1.25 & 0.08 & 0.08 & 0.07 & 1.25 & 0.35 & 0.08 & $0.31 * *$ & 1.25 \\
\hline Perceived vulnerability & 0.11 & 0.07 & 0.11 & 1.27 & 0.10 & 0.07 & 0.11 & 1.27 & 0.08 & 0.07 & 0.09 & 1.27 & 0.13 & 0.07 & $0.14^{*}$ & 1.27 \\
\hline Response efficacy & -0.11 & 0.07 & -0.11 & 1.14 & 0.04 & 0.06 & 0.04 & 1.14 & -0.07 & 0.06 & -0.08 & 1.13 & 0.03 & 0.06 & 0.04 & 1.14 \\
\hline$R^{2}$ & \multicolumn{4}{|c|}{0.27} & \multicolumn{4}{|c|}{0.13} & \multicolumn{4}{|c|}{0.10} & \multicolumn{4}{|c|}{0.24} \\
\hline Adjusted $R^{2}$ & \multicolumn{4}{|c|}{0.26} & \multicolumn{4}{|c|}{0.11} & \multicolumn{4}{|c|}{0.08} & \multicolumn{4}{|c|}{0.22} \\
\hline
\end{tabular}

Notes: $N=193 ;{ }^{*} p<0.05, * * p<0.01$.

The third model is the model for predicting waste reduction behaviors. The results indicate that the overall model was significant, with $\mathrm{F}(4,187)=5.11, p=0.000$. The multiple correlation coefficient (R) was 0.314 , and R square was 0.098 . Also in this regression, multicollinearity was not an issue, as all VIF values were below the threshold value of 10. Moreover, only self-efficacy was a significant factor explaining respondents' engagement in waste reduction behaviors. The last model was the model for predicting reuse and recycle behaviors. The overall model was significant, with $F(4,188)=14.78$, $p=0.000$. The multiple correlation coefficient $(\mathrm{R})$ was 0.489 , and $\mathrm{R}$ square was 0.239 . The VIF indices were also below the VIF-index threshold value of 10 . Of the predictors, the perceived severity of 
adverse consequences caused by environmental impacts of waste disposal was the most significant predictor; its beta-value was 0.305 . Perceived self-efficacy was also significant at $1 \%$, and its beta-value was 0.200 . Perceived vulnerability was significant at $5 \%$, and its beta-value was 0.14 . Only perceived response efficacy had no significant effect on reuse and recycle behaviors.

Overall, the multiple regression analysis results revealed that variables related to PMT well predicted respondents' waste disposal behaviors and reuse and recycle behaviors, as the $\mathrm{R}$ square values of these two models were higher than those of the models for predicting waste reduction and green purchasing behaviors. In addition, many variables related to PMT could predict waste disposal behaviors and reuse and recycle behaviors, whereas waste reduction and green purchasing behaviors could only be predicted by self-efficacy.

\section{Discussions and Implications for the Development of Communication Campaigns}

An assumption in this study was that behavioral change is important for reducing waste management problems in cities. PMT was employed to investigate whether threat appraisal and coping appraisal could explain people's decision to engage in each type of SWMB. According to the results of multiple regression analyses, PMT was able to predict some types of SWMBs, particularly behaviors that do not require people to pay anything, such as waste separation. SWMBs that potentially provide people with economic benefits could also be effectively explained by PMT. Those behaviors are reuse and recycle behaviors, including reusing or recycling plastic bags and bottles, and using single-sided paper for writing notes. Alternatively, PMT did have a significant effect on SWMBs associated with some additional costs, such as purchasing green products. In Thailand, the cost of a green product is generally higher than that of a normal product. It was also found that attributes of PMT were less able to explain SWMBs that require considerable effort and disrupt people's convenient lifestyles. For instance, customers typically receive a plastic bag when purchasing goods, or a container when buying foods or drinks. According to the result of multiple regression analyses, such behaviors (e.g., refusing to receive a plastic bag when purchasing a few items, using a reusable instead of a single-use container, and using a cotton bag instead of plastic bags) can be less explained by attributes of PMT.

Considering the factors influencing each type of SWMB, respondents' perceived response efficacy did not influence all types of SWMBs. Although the participants believed that individuals' waste management behaviors can solve waste management problems and the consequences of waste disposal, many still do not commit to such behaviors. Other factors must be involved to change people's behaviors. This finding contradicts the results of an investigation conducted by Keshavarz and Karami [40], who found that perceived response efficacy highly affected farmers' engagement in pro-environmental behaviors during a drought. This implies that different types of pro-environmental behaviors might be explained differently by different attributes of PMT. On the contrary, perceived self-efficacy had a significant and positive effect on all types of SWMB. Thus, people may decide to perform SWMBs if they think that it is possible to perform them. This finding is in line with the results of prior studies [37,50,51]. Tabernero and Hernandez [52], for instance, found that people with high perceived self-efficacy reported high engagement in recycling behaviors. Self-efficacy was also found to be a significant predictor of pro-environmental behaviors in many studies that applied the theory of planned behaviors [53,54].

Regarding the influence of threat appraisals on SWMBs, the result showed that not all types of SWMBS were affected by perceived severity and vulnerability. It is noteworthy that green purchasing behaviors were not significantly affected by either perceived severity or vulnerability. However, individual decisions to practice green purchasing might be dependent upon other factors, such as environmental attitudes, knowledge, and income level. This is because green purchasing practices sometimes create additional expenditures and rely more on individuals' general environmental awareness than the intention to protect themselves from environmental threats caused by waste disposal. Similar to green purchasing behaviors, waste avoidance behaviors were also only influenced by self-efficacy, whereas variables related to threat appraisal did not affect such behaviors at all. In this 
way, it could be concluded that attributes of PMT might not be well-suited to explore both green purchasing and waste avoidance behaviors. In addition, to promote these behaviors, other types of factors should be further investigated.

Reuse and recycle behaviors were affected by both the respondents' perceived severity and vulnerability. This finding is related to results from previous studies indicating a relationship between individual perceived environmental risks and pro-environmental behavior $[50,55,56]$, such as hybrid vehicle ownership [56], electric vehicle adoption [50], and pro-environmental in a drought (e.g., biodiversity conservation and water resource protection) [40]. In the present study, reuse and recycle behaviors are simple, well-known measures that could be practiced in general. Certain types of behaviors, such as double-sided printing and using single-sided paper for writing notes, could also provide some economic benefits. When people feel that the environmental risks associated with increasing metropolitan solid waste exists, they might first decide to perform behaviors that can be carried out simply and have no cost. As Homburg and Stolberg [57] found, the combination of perceived risks and self-efficacy could motivate people to engage in ecological behaviors. In addition to being influenced by self-efficacy, waste disposal behaviors were affected by the perceived severity of environmental pollutants caused by solid waste disposal. As waste disposal behaviors potentially reduce environmental problems caused by ineffective waste disposal, people might feel that the severity of adverse consequences would be minimized by practicing appropriate waste disposal. This finding corresponds to studies carried out by Kim et al. [38], who found that people's perceived severity of consequences associated with climate change and self-efficacy were significantly positive predictors of environmental behaviors that aim to minimize the effects of climate change. Overall, this study could suggest that PMT is well suited to the investigation of certain types of SWMBs, particularly low-cost and simple waste management behaviors, whereas SWMBs that require financial and mental effort may not be fully explained by PMT.

Additionally, based on the findings of this study, communication campaigns for enhancing waste management behaviors can be developed. Apparently, communicating information that could enhance people's perceived self-efficacy might positively influence people's engagement in all types of SWMBs, as the results revealed that all types of SWMBs could be explained by self-efficacy. Therefore, if clear sets of knowledge are provided which present environmental practices that people can perform to protect and conserve the natural environment, people's perceived self-efficacy can be enhanced [58,59]. Such information might be, for instance, how to practice waste separation or how to make use of solid waste. Information relevant to the severity of adverse consequences of environmental contamination generated from waste disposals also potentially enhances the motivation to engage in reuse and recycle and waste disposal behaviors, as the findings revealed that people's perceived severity significantly affected these two types of SWMBs. The findings also indicated that variations in the level of perceived vulnerability also significantly influenced the level of engagement in reuse and recycle behaviors. Therefore, communicating information relevant to an individual's perceived vulnerability to environmental contamination, such as the types of health impairment caused by polluted air or water, might be able to enhance these two types of SWMBs as well. In conclusion, encouraging people to engage in each type of SWMB seems to require different communication strategies.

\section{Conclusions}

This study applied the protection motivation theory (PMT) to investigate citizens' engagement in sustainable waste management behaviors (SWMBs). Based on PMT, four factors, including perceived severity of catastrophic consequences of environmental pollutants caused by waste disposal processes, perceived probability of receiving impacts, perceived response efficacy, and self-efficacy, were investigated regarding their effect on citizens' engagement in SWMBs-including waste avoidance, green purchasing behaviors, reuse and recycle, and waste disposal behaviors. Multiple linear regression analyses were performed, and the results revealed that perceived response efficacy did not influence all types of SWMBs. In contrast, perceived self-efficacy had a significant effect on all types of SWMBs. 
Perceived severity had a significant influence on waste disposal behaviors and reuse and recycle behaviors; whereas, perceived probability of receiving impacts or vulnerability had a significant effect on reuse and recycle behaviors. Based on the findings, this study suggested that PMT can be used to investigate some types of SWMBs, particularly low-cost and simple behaviors that require less effort.

To promote office workers' SWMBs, policymakers such as organisational leaders can apply the results of this investigation to the development of risk-communication strategies. The dissemination of information about the environmental and health impacts of solid waste disposal on office workers can motivate the workers to engage in reusing and recycling behaviours and waste-disposal behaviours such as waste separation. Communicating information about the individual susceptibility to environmental pollution caused by solid waste can also influence office workers' motivation to take part in reusing and recycling. On the other hand, since an individual's threat appraisal does not influence office workers' engagement in waste avoidance and green purchasing behaviours, the dissemination of these two types of information will not eventually lead to the workers' enhanced motivation to engage in these behaviours.

In terms of the role of self-efficacy, the study reveals that an office worker's perceived self-efficacy has a significant influence on his or her motivation to engage in all types of SWMBs. Communicating information that potentially increases workers' recognition of their capability to perform SWMBs can raise their motivation. Workers should be given information on various types of environmental action strategies and the seriousness of waste disposal problems, so that the workers can realise the importance of taking action and know which actions can minimise the impacts of waste. This study also suggests that to promote office workers' engagement in waste avoidance and green purchasing behaviours, other relevant factors should be studied, since many attributes of PMT did not affect workers' decision to engage in those behaviours.

\section{Limitations of the Study}

Although this study has provided basic understandings on how PMT attributes could predict office workers' engagement in SWMBs, the results might not be properly able to be generalized to general workers due to the small sampling size. Further research which could include more participants is recommended. In addition, $\mathrm{R}$ square of multiple regression models were also low; therefore, other relevant factors should be included in the analysis in order to increase the power of the models to predict SWMBs of office workers.

Acknowledgments: This study was supported by the School of Liberal Arts, King Mongkut's University of Technology Thonburi, Bangkok, Thailand. The author also acknowledges the financial support provided by King Mongkut's University of Technology Thonburi. Most importantly, the author would like to acknowledge all participants who involved in questionnaire surveys.

Conflicts of Interest: The author declares no conflict of interest.

\section{References}

1. Department of Public Cleansing. Waste Minimization Project in Bangkok City; Department of Public Cleansing, Bangkok Metropolitan Administration: Bangkok, Thailand, 2000. (In Thai)

2. Department of Public Cleansing. Solid Waste and Night soil Management in Bangkok; Department of Public Cleansing, Bangkok Metropolitan Administration: Bangkok, Thailand, 2005.

3. Muttamara, S.; Candelaria, L.S.; Phunsiri, S. Solid Waste Recycling, Disposal and Management in Bangkok Environmental Engineering Program School of Environment; Resources and Development Asian Institute of Technology: Bangkok, Thailand, 2002.

4. Chinda, T.; Leewattana, N.; Leeamnuayjaroen, N. The Study of Landfill Situations in Thailand. In Proceedings of the 1st Mae Fah Luang University International Conference, Changrai Rai, Thailand, 29 November-1 December 2012; pp. 1-8.

5. Wiwanitkit, $\mathrm{V}$. Waste landfill site fire crisis in Thailand; sulfur dioxide pollution and estimation of cancer risk. South Asian J. Cancer 2014, 3, 185-186. [CrossRef] [PubMed] 
6. Wiwanitkit, V. Thai waste landfill site fire crisis, particular matter 10, and risk of lung cancer. J. Can. Res. Ther. 2016, 12, 1088-1089. [CrossRef] [PubMed]

7. US-EPA. 2013 Non-Hazardous Solid Waste Management Hierarchy. Available online: http:/ /www.epa.gov / solidwaste/nonhaz/municipal/hierarchy.htm (accessed on 16 June 2017).

8. Xiao, L.; Zhang, G.; Zhu, Y.; Lin, T. Promoting public participation in household waste management: A survey based method and case study in Xiamen city, China. J. Clean. Prod. 2017, 144, 313-322. [CrossRef]

9. Budică, I.; Busu, O.V.; Dumitru, A.; Purcaru, M.-L. Waste management as commitment and duty of citizens. Pol. J. Manag. Stud. 2015, 11, 7-16.

10. James, O.; Moseley, A. Does performance information about public services affect citizens' perceptions, satisfaction, and voice behaviour? Field experiments with absolute and relative performance information. Public Adm. 2014, 92, 493-511. [CrossRef]

11. Castagna, A.; Casagranda, M.; Zeni, A.; Girelli, E.; Rada, E.C.; Ragazzi, M.; Apostol, T. 3R'S from citizens point of view and their proposal from a case-study. UPB Sci. Bull. Ser. D 2013, 75, 253-264.

12. Matsui, Y.; Tanaka, M.; Ohsako, M. Study of the effect of political measures on the citizen participation rate in recycling and on the environmental load reduction. Waste Manag. 2007, 27, S9-S20. [CrossRef] [PubMed]

13. Papargyropoulou, E.; Lozano, R.; Steinberger, J.K.; Wright, N.; Ujang, Z.B. The food waste hierarchy as a framework for the management of food surplus and food waste. J. Clean. Prod. 2014, 76, 106-115. [CrossRef]

14. Permana, A.S.; Towolioe, S.; Aziz, N.A.; Ho, C.S. Sustainable solid waste management practices and perceived cleanliness in a low income city. Habitat Int. 2015, 49, 197-205. [CrossRef]

15. Knauf, M. Waste hierarchy revisited-an evaluation of waste wood recycling in the context of EU energy policy and the European market. For. Policy Econ. 2015, 54, 58-60. [CrossRef]

16. UC Davis. 2008 The 4 R's of Waste Reduction. Available online: http://sustainability.ucdavis.edu/topics / waste_reduction/index.html (accessed on 16 June 2017).

17. First Nations of Quebec and Labrador Sustainable Development Institute. 2008 Reduce, Reuse, Recycle and Recover Waste: A 4R's Guide for the First Nations Communities of Quebec and Labrador. Available online: www.iddpnql.ca/an/documents/4rsguide.pdf (accessed on 16 June 2017).

18. Ávila, C.; Cedano, K.; Martínez, M. Sustainability analysis of waste to energy strategies for municipal solid waste treatment. Int. J. Environ. Sustain. 2017, 13, 1-14. [CrossRef]

19. Guerrero-Lemus, R.; Shephard, L.E. Waste-to-energy. In Lecture Notes in Energy; Springer: Berlin, Germany, 2017; Volume 38, pp. 301-322.

20. Cucchiella, F.; D'Adamo, I.; Rosa, P. Urban waste to energy (WTE) plants: A social analysis. JP J. Heat Mass Transf. 2016, 13, 421-444. [CrossRef]

21. Mastellone, M.L. Waste Management and Clean Energy Production from Municipal Solid Waste; Nova Science Publishers: Hauppauge, NY, USA, 2015; pp. 1-173.

22. Rada, E.C. Energy from municipal solid waste. WIT Trans. Ecol. Environ. 2014, 2, 945-958.

23. ECOTEC Research and Consulting Ltd. 2000 beyond the Bin: The Economics of Waste Management Options. Available online: www.foe.co.uk/resource/reports/economics_waste_options.pdf (accessed on 16 June 2017).

24. European Parliament and European Council. 2008 Directive 2008/98/EC on Waste (Waste Framework Directive). Available online: ec.europa.eu/environment/waste/framework/ (accessed on 16 June 2017).

25. Vlek, C.; Steg, L. Human behavior and environmental sustainability: Problems, driving forces and research topics. J. Soc. Issues 2007, 63, 1-19. [CrossRef]

26. Gardner, G.T.; Stern, P.C. Environmental Problems and Human Behavior, 2nd ed.; Pearson Custom Publishing: Boston, MA, USA, 2002.

27. Ajzen, I. The theory of planned behavior. Organ. Behav. Decis. Process. 1991, 50, 179-211. [CrossRef]

28. Stern, P.C. Towards a coherent theory of environmentally significant behavior. J. Soc. Issues 2000, 56, 407-424. [CrossRef]

29. Rogers, R.W. A Protection Motivation Theory of fear appeals and attitude change. J. Psychol. 1975, 91, 93-114. [CrossRef] [PubMed]

30. Rogers, R.W. Cognitive and physiological processes in fear appeals and attitude change: A revised theory of protection motivation. In Social Psychophysiology: A Sourcebook; Cacioppo, B.L., Petty, R.E., Eds.; Guilford Press: London, UK, 1983. 
31. Prentice-Dunn, S.; Rogers, R.W. Protection motivation theory and preventive health: Beyond the health belief model. Health Educ. Res. 1986, 1, 153-161. [CrossRef]

32. El-Fadelf, M.; Findikakis, A.N.; Leckie, J.O. Environmental Impacts of Solid Waste Landfilling. J. Environ. Manag. 1997, 50, 1-25. [CrossRef]

33. Wu, Y.; Stanton, B.F.; Li, X.; Galbraith, J.; Cole, M. Protection motivation theory and adolescent drug trafficking: Relationship between health motivation and longitudinal risk involvement. J. Pediatr. Psychol. 2005, 30, 127-137. [CrossRef] [PubMed]

34. Kelly, M.P.; Barker, M. Why is changing health-related behavior so difficult? Public Health 2016, 136, $109-116$. [CrossRef] [PubMed]

35. Grothmann, T.; Patt, A. Adaptive capacity and human cognition: The process of individual adaptation to climate change. Glob. Environ. Chang. 2005, 15, 199-213. [CrossRef]

36. Martin, I.; Bender, H.; Raish, C. What motivates individuals to protect themselves from risks: The case of Wildland fires. Risk Anal. 2007, 27, 887-900. [CrossRef] [PubMed]

37. Bubeck, P.; Botzen, W.J.W.; Aerts, J.C.J.H. A review of risk perceptions and other factors that influence flood mitigation behavior. Risk Anal. 2012, 32, 1481-1495. [CrossRef] [PubMed]

38. Kim, S.; Jeong, S.; Hwang, Y. Predictors of pro-environmental behaviors of American and Korean students the application of the theory of reasoned action and protection motivation theory. Sci. Commun. 2013, 35, 168-188. [CrossRef]

39. Marquit, J.D. Threat Perception as a Determinant of Pro-Environmental Behaviors: Public Involvement in Air Pollution Abatement in Cache Valley, Utah. Master's Thesis, Utah State University, Logan, UT, USA, 2008; p. 188.

40. Keshavarz, M.; Karami, E. Farmers' pro-environmental behavior under drought: Application of protection motivation theory. J. Arid Environ. 2016, 127, 128-136. [CrossRef]

41. Bangkok State of the Environment 2012. Available online: http://203.155.220.174/pdf/ BangkokStateOfEnvironment2012RevisedEdition.pdf (accessed on 16 June 2017).

42. Environment Department Bangkok. 2016 Waste Amount. Available online: http://203.155.220.174/modules. php?name=activeshow_mod\&file=showpage\&new_topic=12 (accessed on 16 June 2017).

43. Environment Department Bangkok. Government Action Plan 2016. Available online: http://203.155.220.174/ uploads/plan59.pdf (accessed on 16 June 2017).

44. Climate and Clean Air Coalition. Municipal Solid Waste Initiative. Available online: http://waste.ccacknowledge.net/ (accessed on 16 June 2017).

45. Warriner, G.K.; McDougall, G.H.; Claxton, J.D. Any data or none at all? Living with inaccuracies in self-reports of residential energy consumption. Environ. Behav. 1984, 16, 503-526. [CrossRef]

46. Fujii, E.T.; Hennesy, M.; Mak, J. An evaluation of the validity and reliability of survey response data on household electricity conservation. Environ. Rev. 1985, 9, 93-104. [CrossRef]

47. Boer, H.; Seydel, E. Protection motivation theory. In Predicting Health Behavior: Research and Practice with Social Cognition Models; Connor, M., Norman, P., Eds.; Open University Press: Buckingham, PA, USA, 1996; pp. 95-120.

48. Kennedy, P. A Guide to Econometrics, 5th ed.; MIT Press: Cambridge, MA, USA, 2003.

49. Field, A.P. Discovering Statistics Using SPSS: And Sex and Drugs and Rock " $n$ " Roll, 3rd ed.; Sage: London, UK, 2009.

50. Bockarjova, M.; Steg, L. Can Protection Motivation Theory predict pro-environmental behavior? Explaining the adoption of electric vehicles in the Netherlands. Glob. Environ. Chang. 2014, 28, 276-288. [CrossRef]

51. Plotnikoff, R.C.; Trinh, L.; Courneya, K.S.; Karunamuni, N.; Sigal, R.J. Predictors of aerobic physical activity and resistance training among Canadian adults with type 2 diabetes: An application of the protection motivation theory. Psychol. Sport Exerc. 2009, 10, 320-328. [CrossRef]

52. Tabernero, C.; Hernandez, B. Self-Efficacy and intrinsic motivation guiding environmental behavior. Environ. Behav. 2010, 43, 658-675. [CrossRef]

53. Ajzen, I.; Fishbein, M. Attitudes and the Attitude-Behavior Relation: Reasoned and Automatic Processes; John Wiley: Hoboken, NJ, USA, 2004.

54. Fernandez-Manzanal, R.; Serra, L.M.; Morales, M.J.; Carrasquer, J.; Rodriguez-Barreiro, L.M.; Del Valle, J.; Murillo, M.B. Environmental behaviors in initial professional development and their relationship with university education. J. Clean. Prod. 2015, 108, 830-840. [CrossRef] 
55. Kahn, M.E. Do greens drive Hummers or hybrids? Environmental ideology as a determinant of consumer choice. J. Environ. Econ. Manag. 2007, 54, 129-145. [CrossRef]

56. Ozaki, R.; Sevastyanova, K. Going hybrid: An analysis of consumer purchase motivations. Energy Policy 2011, 39, 2217-2227. [CrossRef]

57. Homburg, A.; Stolberg, A. Explaining pro-environmental behavior with a cognitive theory of stress. J. Environ. Psychol. 2006, 26, 1-14. [CrossRef]

58. Eigner, S.; Schmuck, P. Motivating collective action: Converting to sustainable energy sources in a german community. In Psychology of Sustainable Development; Schmuck, P., Schultz, W.P., Eds.; Kluwer Academic Publishers: Boston, MA, USA, 2002; pp. 241-256.

59. Geller, E.S. Actively caring for the environment: An integration of behaviourism and humanism. Environ. Behav. 1995, 27, 184-195. [CrossRef]

(C) 2017 by the author. Licensee MDPI, Basel, Switzerland. This article is an open access article distributed under the terms and conditions of the Creative Commons Attribution (CC BY) license (http://creativecommons.org/licenses/by/4.0/). 